\title{
Is case triaging a useful tool for emergency surgeries? A review of 106 trauma surgery cases at a level 1 trauma center in South Africa
}

\author{
Sharfuddin Chowdhury ${ }^{1 *}$ (D, Andrew John Nicol ${ }^{2}$, Mahammed Riyaad Moydien ${ }^{3}$, Pradeep Harkison Navsaria ${ }^{4}$ \\ and Luis Felipe Montoya-Pelaez ${ }^{5}$
}

\begin{abstract}
Background: The optimal timing for emergency surgical interventions and implementation of protocols for trauma surgery is insufficient in the literature. The Groote Schuur emergency surgery triage (GSEST) system, based on Cape Triaging Score (CTS), is followed at Groote Schuur Hospital (GSH) for triaging emergency surgical cases including trauma cases. The study aimed to look at the effect of delay in surgery after scheduling based on the GSEST system has an impact on outcome in terms of postoperative complications and death.

Methods: Prospective audit of patients presenting to GSH trauma center following penetrating or blunt chest, abdominal, neck and peripheral vascular trauma who underwent surgery over a 4-month period was performed. Post-operative complications were graded according to Clavien-Dindo classification of surgical complications.

Results: One-hundred six patients underwent surgery during the study period. One-hundred two (96.2\%) cases were related to penetrating trauma. Stab wounds comprised 71 (67\%) and gunshot wounds (GSW) 31 (29.2\%) cases. Of the 106 cases, 6, 47, 40, and 13 patients were booked as red, orange, yellow, and green, respectively. The median delay for green, yellow, and orange cases was within the expected time. The red patients took unexpectedly longer (median delay $48 \mathrm{~min}$, IQR 35-60 min). Thirty-one (29.3\%) patients developed postoperative complications. Among the booked red, orange, yellow, and green cases, postoperative complications developed in 3, 18, 9, and 1 cases, respectively. Only two (1.9\%) postoperative deaths were documented during the study period. There was no statistically significant association between operative triage and post-operative complications $(p=0.074)$.
\end{abstract}

Conclusion: Surgical case categorization has been shown to be useful in prioritizing emergency trauma surgical cases in a resource constraint high-volume trauma center.

Keywords: Emergency surgery case triage, Trauma surgery, Postoperative complication, Outcome

\section{Background}

Trauma is an epidemic in South Africa [1]. The significant number of our emergency general surgical cases is injury related. These are potentially life-threatening, and urgent surgical intervention is required to reduce mortality and morbidity.

\footnotetext{
* Correspondence: dr_smahmud@yahoo.com

${ }^{1}$ Consultant and head of Trauma Surgery, King Saud Medical City, 7790 Al-Imam Abdul Aziz Ibn Muhammad Ibn Saud, Ulaishah, Riyadh 12746, Kingdom of Saudi Arabia

Full list of author information is available at the end of the article
}

Emergency surgical cases are admitted to health institutions in an unplanned and unscheduled manner. Patients usually present with acute surgical conditions that require prompt and focused treatment to avoid increased morbidity and mortality. Currently, no specific national or provincial guidelines exist in South Africa for the categorization or triaging of emergency surgical cases. In the current climate of shrinking elective theater time and increasing surgical waiting time, the present focus is to decrease waiting times by addressing issues that have a detrimental effect on overall theater 
efficiency. However, emergency surgical caseloads form a significant and increasing percentage of all patients utilizing theater facilities. Finding ways to manage better this category of patients should result in more efficient utilization of available theater time without impinging on the throughput of cases on elective slates. Given this, a policy document or guideline was introduced at Groote Schuur Hospital (GSH) for use in the categorization and prioritization of emergency surgical cases before operative surgical management. At GSH, the Groote Schuur emergency surgery triage (GSEST) system is based on similar principles to the Cape Triaging Score (CTS) [2]. The color coding categories are similar, but the definitions and emphasis relating to levels of surgical acuity, and urgency for operative intervention differ. The surgical team admitting a patient after consultation with the anesthetist handles the initial categorization of the case.

The study aimed to look at the effect of delay in surgery after scheduling based on the GSEST system has an impact on outcome in terms of postoperative complications and death.

\section{Methods}

The University of Cape Town (UCT) Human Research Ethics Committee (HREC) approved the study. We conducted a descriptive, non-interventional, observational study based on the prospective analysis of data collected during 1 December 2013 to 31 March 2014. All adult (age $>13$ years) acute trauma admissions presenting with penetrating or blunt chest, abdominal, neck, and peripheral vascular injury who underwent surgery were included. Burns, isolated head, orthopedic, hand, and maxillofacial trauma patients were excluded as the respective specialties managed these patients. Collected data included: patient demographic details, mechanism of injury, time of injury, Injury Severity Score (ISS), time of booking the case, triage color code, the delay from scheduling to the start of the case, reasons for the delay, and outcome regarding postoperative complications and death.

Emergency cases were scheduled according to priority as red, orange, yellow, and green for operation (Table 1). Prioritization was done by the attending trauma surgeon based on patient's hemodynamics after discussion with the anesthetist.

The red cases are an immediate priority (resuscitation with immediate operation cases). These cases usually present with hemorrhage or bleeding, requiring instant, life-saving surgical hemostasis. The orange categories are a very urgent priority (potentially life/limb threatening pathology) that should be done within $2 \mathrm{~h}$. The yellow groups are an urgent priority (significant pathology) that should be done in $6 \mathrm{~h}$, and the green cases are a delayed priority (minor injury/illness) that should
Table 1 Groote Schuur emergency surgery triage (GSEST) system

\begin{tabular}{|c|c|c|}
\hline Icon & $\begin{array}{l}\text { Case } \\
\text { category }\end{array}$ & Parameters \\
\hline Red & Immediate & $\begin{array}{l}\text { Immediate life-saving operation, resuscitation } \\
\text { simultaneous with surgical treatment, e.g., } \\
\text { resuscitative laparotomy, ruptured aortic aneurysm } \\
\text { threatened airway, cord prolapse, fetal bradycardia }\end{array}$ \\
\hline Orange & Expedited & $\begin{array}{l}\text { Operation as soon as possible after resuscitation } \\
\text { (within } 1 \text { to } 2 \text { hours), e.g., ruptured ectopic } \\
\text { pregnancy, leaking aortic aneurysm, cranial } \\
\text { decompression, positive DPL in multiple traumas, } \\
\text { threatened limb, emergent fetal concern }\end{array}$ \\
\hline Yellow & Urgent & $\begin{array}{l}\text { Operation within } 6 \text { h of booking, e.g., compound } \\
\text { fractures, appendicitis, incarcerated hernia/intestinal } \\
\text { obstruction, EUA for non-accidental injuries }\end{array}$ \\
\hline Green & Emergent & $\begin{array}{l}\text { Operation not immediately life or limb saving but } \\
\text { have to be done within } 24 \mathrm{~h} \text { of booking, e.g., ORIF of } \\
\text { simple fractures, bleeding hemorrhoids, I\&D abscess }\end{array}$ \\
\hline Blue & Scheduled & $\begin{array}{l}\text { Semi-urgent cases, to be done within } 72 \mathrm{~h} \text {. Operation } \\
\text { during in hours on next available slate if possible }\end{array}$ \\
\hline
\end{tabular}

be done within $24 \mathrm{~h}$. Green cases become yellow after $24 \mathrm{~h}$. Yellow cases become orange after $6 \mathrm{~h}$. Booked cases are assessed on an ongoing basis and recategorized as required. Post-operative complications were categorized according to the updated ClavienDindo classification of surgical complications [3, 4].

Categorical variables were evaluated using frequency tables. Associations between categorical variables were determined by contingency tables and chi-square tests of association. Numerical variables were evaluated with summary statistics (median, interquartile range, etc.). Relationships between numerical and categorical variables were determined using non-parametric tests: Mann-Whitney in instances where the categorical variable has two categories and Kruskal-Wallis otherwise. A $p$-value of $<0.05$ was considered as statistically significant.

\section{Results}

One-hundred six patients underwent surgery during the study period with a higher male to female ratio of 14:1. The median age was 26 (IQR 22-32) years. Onehundred two $(96.2 \%)$ cases were related to penetrating trauma. Stab wounds comprised $71(67 \%)$ and gunshot wounds (GSW) 31 (29.2\%) cases. On presentation 82 (77.4\%), patients were admitted with ISS of greater than 15 (5-48). Trauma surgical procedures included laparotomy (48), vascular (27), subxiphoid pericardial window (13), thoracotomy (4), and sternotomy (1). There were also 13 other relatively non-urgent procedures such as debridement, removal of Foley's cath used for penetrating neck wound tamponade, skin grafting for fasciotomy wounds, etc. Of 106 cases, 6, 47, 40, and 13 cases were booked as red, orange, yellow, and green, respectively. 
The median delay for green, yellow and orange cases was within expected time. The red patients took unexpectedly longer (median delay $48 \mathrm{~min}, \mathrm{IQR} 35-60 \mathrm{~min}$ ) to reach the theater (Table 2).

The main $(49.1 \%)$ reason for the delay in starting the trauma cases was a priority of another emergency (general surgical, gynecological, etc.) booked in that category. Out of six red cases, three were delayed due to unavailability of theater or unable to open an additional theater immediately at that moment (Table 3 ). One red patient died who presented with a thoracic GSW was unstable on presentation and needed an emergency room thoracotomy and delay to shift to the theater was 55 min after booking.

Thirty-one (29.3\%) patients developed postoperative complications (Table 4). Among the booked red, orange, yellow, and green cases, postoperative complications developed in 3, 18, 9, and 1 cases, respectively (Table 5). There was no statistically significant association between operative triage and post-operative complications $(p=0.074)$.

\section{Discussion}

Emergency surgical cases differ from elective cases that are planned. During planned or elective operation the length of surgery, hospital stay, and morbidity and mortality can be predicted or inferred. Conversely, emergency surgical cases present in an unpredicted fashion. Prompt, efficient and appropriate treatment of emergency surgical cases is a cost-effective strategy that has the potential to reduce the length of hospital stay, use of high care and intensive care facilities as well as the use of laboratory and other investigative procedures.

The concept of triage is imperative to manage multiple emergency cases with competing and diverse needs. Deficiency of a triage system leads to longer waiting times, poor clinical risk assessment, and management with subsequently increased morbidity and mortality [2]. An efficient triage system minimizes the risk to the patient and promotes effective use of available resources. The rationale and practice of triaging in mass casualty incidents are accepted worldwide [5]. Different triage systems exist for prehospital assessment and in-hospital casualty triage [6-8], yet no widely accepted methods exist for theater bookings. Triage systems should be implemented for the

Table 2 Operative triage vs. delay (min) from booking to operation

\begin{tabular}{lllll}
\hline Color code & $\begin{array}{l}\text { Expected time } \\
\text { to start surgery }\end{array}$ & $\begin{array}{l}\text { Number } \\
\text { of cases }\end{array}$ & $\begin{array}{l}\text { Median } \\
\text { delay (min) }\end{array}$ & IQR \\
\hline Red & Immediate & 6 & 48 & $35-60$ \\
Orange & $<2 \mathrm{~h}$ & 47 & 120 & $53-185$ \\
Yellow & $<6 \mathrm{~h}$ & 40 & 213 & $113-300$ \\
Green & $<24 \mathrm{~h}$ & 13 & 110 & $65-265$ \\
\hline
\end{tabular}

Table 3 Operative triage vs. Reasons for the delay

\begin{tabular}{llllll}
\hline Cause & Red $(\mathrm{N})$ & Orange $(\mathrm{O})$ & Yellow $(\mathrm{Y})$ & Green $(\mathrm{N})$ & Total $(\mathrm{N})(\%)$ \\
\hline $\begin{array}{l}\text { No theater } \\
\text { available }\end{array}$ & 3 & 26 & 11 & 2 & $42(39.6 \%)$ \\
$\begin{array}{l}\text { Priority of } \\
\text { other case }\end{array}$ & 0 & 16 & 26 & 10 & $52(49.1 \%)$ \\
$\begin{array}{l}\text { Delay in shift } \\
\text { to theater }\end{array}$ & 3 & 5 & 3 & 1 & $12(11.3 \%)$ \\
Total & 6 & 47 & 40 & 13 & $106(100 \%)$ \\
\hline
\end{tabular}

$N$ Number of patients

care of surgical emergencies [5] including trauma surgery. Early management of trauma cases is pertinent, as a delay to operative management may increase the risk of adverse outcomes [9].

Triaging of emergency surgical cases were introduced at GSH for the categorization and prioritization of emergency surgical cases at the point of contact with the surgical team before the operative surgical management of a patient. The objective is to improve communication and teamwork between anesthetic, surgical, and nursing personnel involved in the care of these patients.

\section{Limitations}

It is an observational study of a small number of trauma cases over 4-month period. The GSEST system describes the emergencies of all kinds including obstetric and gynecological. There are a few general surgical trauma diagnoses are included. It would be useful to have few more parameters perhaps in a separate column, e.g., what general surgical trauma diagnoses fit into the different category?

\section{Future directions}

Every minute is essential for the severely injured trauma patient. Delays at any stage from the scene to the operating theater may impact negatively on the outcome regarding complications and death [9]. Triaging is a crucial element for such cases. A more extensive comparative research is required before and after the

Table 4 Types of complications according to Clavien-Dindo classification

\begin{tabular}{ll}
\hline Clavien-Dindo Grading & $\begin{array}{l}\text { Postoperative complications } \\
\text { (number of patients) }\end{array}$ \\
\hline II & Wound sepsis (5), lleus (1) \\
IIIa & Pneumonia (1) \\
IIIb & Loculated haemothorax (1) \\
IVa & Empyema of chest (3) \\
IVb & Acute kidney injury (6), respiratory failure (9) \\
V & Multiorgan dysfunction (3) \\
Total & Death (2) \\
\hline
\end{tabular}


Table 5 Operative triage vs. complications (yes/no)

\begin{tabular}{llll}
\hline Color code & Complications & No complications & Total \\
\hline Red & 3 & 3 & 6 \\
Orange & 18 & 29 & 47 \\
Yellow & 9 & 31 & 40 \\
Green & 1 & 12 & 13 \\
Total & 31 & 75 & 106 \\
\hline
\end{tabular}

introduction of GSEST system to look at the effectiveness including over- and under-triage rate, accuracy, likelihood ratios, etc.

\section{Conclusion}

Emergency trauma surgical cases vary in degree of acuity and complexity. Categorization allows the surgical and anesthetic teams to plan perioperative optimization and prioritize treatment of patients based on their clinical status and expected a progression of the disease. Assessing the South Africa's excessive rate of penetrating wounds needing an emergency operation, it is of utmost importance to create, implement, use, and disseminate national guidelines and standard for these to improve outcomes and life losses.

\section{Acknowledgements}

Research Center, King Saud Medical City, Riyadh, KSA.

\section{Funding}

Not applicable

\section{Availability of data and materials}

Please contact the corresponding author for data requests

\section{Authors' contributions}

SC, AJN, and LFMP conceived and designed the study. SC and MRM participated in the conduct of the study. SC prepared the manuscript. AJN and PHN reviewed the manuscript. All authors read and approved the final manuscript.

\section{Ethics approval and consent to participate}

The study was a University of Cape Town (UCT) Human Research Ethics Committee (HREC) approved, and the reference number is 440/2013.

\section{Consent for publication}

Not applicable

\section{Competing interests}

The authors declare that they have no competing interests.

\section{Publisher's Note}

Springer Nature remains neutral with regard to jurisdictional claims in published maps and institutional affiliations.

\section{Author details}

${ }^{1}$ Consultant and head of Trauma Surgery, King Saud Medical City, 7790 Al-Imam Abdul Aziz Ibn Muhammad Ibn Saud, Ulaishah, Riyadh 12746, Kingdom of Saudi Arabia. ' Head and Director of Trauma Centre, Groote Schuur Hospital and University of Cape Town, Cape Town, South Africa. ${ }^{3}$ Groote Schuur Hospital and University of Cape Town, Cape Town, South Africa. ${ }^{4}$ Deputy Director of Trauma Centre, Groote Schuur Hospital, and University of Cape Town, Cape Town, South Africa. ${ }^{5}$ Department of
Anaesthesia, Groote Schuur Hospital and University of Cape Town, Cape Town, South Africa.

Received: 21 November 2017 Accepted: 18 January 2018

Published online: 24 January 2018

\section{References}

1. Matzopoulos RG, Prinsloo M, Butchart A, et al. Estimating the South African trauma caseload. Int J Inj Control Saf Promot. 2006;13(1):49-51.

2. Wallis $L A$, Gottschalk SB, Wood D, et al. The cape triage score-a triage system for South Africa. S Afr Med J. 2006:96:53-6.

3. Dindo D, Demartines N, Clavien PA. Classification of surgical complications-a new proposal with evaluation in a cohort of 6336 patients and results of a survey. Ann Surg. 2004;240(2):205-13.

4. Clavien PA, Barkun J, de Oliveira ML, et al. The Clavien-Dindo classification of surgical complications_five-year experience. Ann Surg. 2009;250(2):18796.

5. Kluger $Y$, Ben-Ishay $O$, Sartelli $M$, et al. World society of emergency surgery study group initiative on timing of acute care surgery classification(TACS). World J Emerg Surg. 2013;8:17. https://doi.org/10.1186/1749-7922-8-17.

6. Beveridge R, Ducharme J, Janes L, et al. Reliability of the Canadian emergency department triage and acuity scale: interrater agreement. Ann Emerg Med. 1999;34:155-9.

7. Australian College of Emergency Medicine. G24 guidelines on the implementation of the Australasian triage scale in emergency departments. Melbourne: Australian College of Emergency Medicine; 2005.

8. Manchester Triage Group. Emergency triage. Manchester: BMJ Publishing Group; 1997.

9. Chowdhury S, Navsaria PH, Edu S, et al. The effect of emergency medical services response on the outcome of trauma laparotomy at a level 1 trauma centre in South Africa. S Afr J Surg. 2016;54(4):17-21.
Submit your next manuscript to BioMed Central and we will help you at every step:

- We accept pre-submission inquiries

- Our selector tool helps you to find the most relevant journal

- We provide round the clock customer support

- Convenient online submission

- Thorough peer review

- Inclusion in PubMed and all major indexing services

- Maximum visibility for your research

Submit your manuscript at www.biomedcentral.com/submit 